\title{
ULTRASTRUCTURAL AND MICROANALYTICAL RESULTS FROM ECHINODERM CALCITE: IMPLICATIONS FOR BIOMINERALIZATION AND DIAGENESIS OF SKELETAL MATERIAL
}

\author{
David F. Blake, Donald R. Peacor \\ Department of Geological Sciences, University of Michigan, Ann Arbor, MI 48109, U.S.A. \\ and \\ Lawrence F. Allard \\ Department of Materials and Metallurgical Engineering, University of Michigan, Ann Arbor, MI 48109, U.S.A.
}

(Received 9 January 1984)

\begin{abstract}
Magnesian calcite skeletal elements of the modern crinoid echinoderm Neocrinus blakei were studied using high resolution TEM, high voltage TEM and STEM microanalysis. Unlike inorganic magnesian calcites which are compositionally heterogeneous, magnesium in these skeletal calcites is homogeneous to at least the $0.1 \mu \mathrm{m}$ level. While a mosaic structure exists in echinoderm calcite, high voltage TEM reveals the absence of defects or dislocation features which should exist as a consequence of the structure. By comparison, inorganic magnesian calcites show a plethora of defects and dislocation features. High resolution lattice fringe images of the echinoderm calcite exhibit a kinking of fringes between mosaic domains, the boundaries of which are largely coherent. Large scale dislocation structures are not observed. Such a 'stressed' lattice structure, if pervasive, explains conflicting observations concerning the 'single crystal' or 'polycrystalline aggregate' nature of echinoderm calcite. The microstructural and microchemical data demonstrate strong organismal control of skeletal deposition in Echinodermata. Both ultrastructural and compositional heterogeneity/homogeneity should be assessed when determining the susceptibility of skeletal material to diagenetic change.

Index key words: Echinoderm calcite, biomineralization, analytical electron microscopy, skeletal diagenesis, magnesian calcite.
\end{abstract}

\section{INTRODUCTION}

Echinodermata is a phylum of marine invertebrates which includes such diverse organisms as sea stars (Asteroidea), sea urchins (Echinoidea) and sea lilies (Crinoidea). The hard parts of echinoderms have a porous microstructure, referred to as stereom (see Figs. 1(a-b)) and are composed of high-magnesium calcite (Weber, 1969). Each skeletal plate, with few exceptions. behaves optically as if it were a single crystal of calcite (Raup, 1966). It is this rather paradoxical mix of organismal control of morphology and 'inorganic' crystallographic features which has prompted much recent work on echinoderm hard parts, the growth processes of which are

Address all correspondence to first author. significant to an understanding of the general process of biomineralization.

While echinoderm hard parts appear to be single crystals of calcite, fracture surfaces do not exhibit the $\{10.4\}$ cleavage observed in inorganic calcite (e.g. see Fig. 1(b)). Towe (1967) suggested that echinoderm calcite might possess a 'mosaic' structure in which the skeletal calcite was made up of tiny crystallites, slightly misaligned with respect to one another. Later fracture (Nissen, 1969) and single crystal X-ray diffraction (Donnay and Pawson, 1969) studies appeared to suggest that echinoderm hard parts were essentially single crystals of calcite. Recent studies, utilizing 'stress-relaxed fracturing' (O'Neill, 1981) and selected area electron diffraction (Blake and Peacor, 1981) suggest that a pervasive mosaic structure is present. However, the actual 

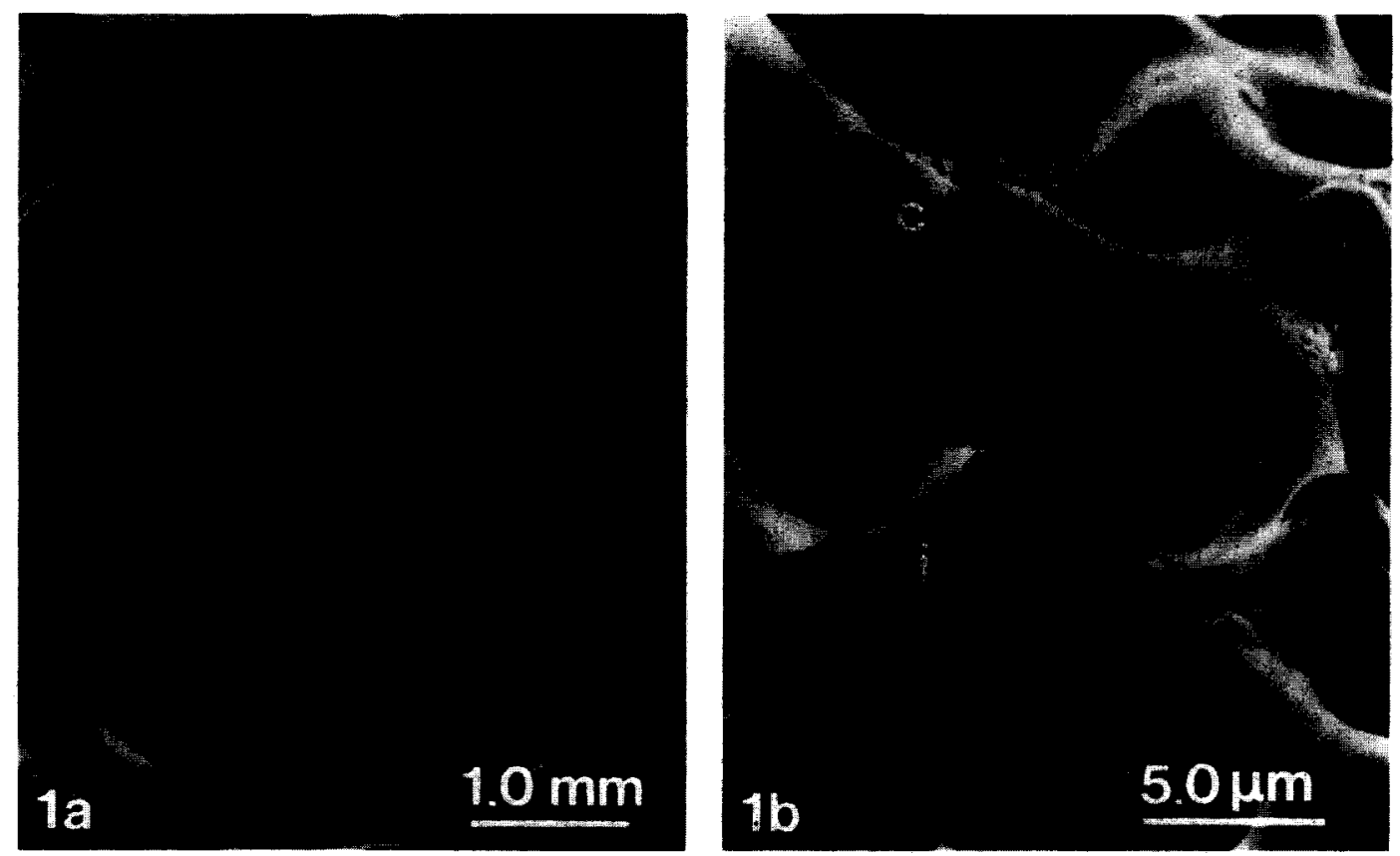

Fig. 1. (a) Low magnification SEM micrograph of $N$. blakei columnal, viewed looking down the morphological axis of the columnal. The five-fold pseudosymmetry, rounded stereom and fenestrate microstructure are typical of skeletal elements of Echinodermata $(\times 17)$. (b) SEM micrograph of crinoid stereom showing rounded stereom structure and conchoidal (c) and irregular (i) fracture surfaces typical of echinoderm calcite $(\times 3800)$.

imperfections which relate to the mosaic structure have never been directly observed.

The microstructure of the skeletal calcite must result from original skeletal growth processes. In addition, the susceptibility of skeletal material to diagenetic processes may be influenced as much by skeletal ultrastructure as by composition. Insight into both the biomineralization process and the diagenetic potential of such metastable phases may be gained by studying these ultrastructural features in detail.

O'Neill (1981) suggested that variations in $\mathrm{Mg}$ content could explain the morphologically curved surfaces present in the echinoderm stereom, since magnesium incorporation in the crystal structure would serve to reduce the calcite lattice parameters. Magnesium heterogeneity has been reported in some echinoderm skeletal elements (Weber, 1969; Davies et al., 1972), but this heterogeneity appears to be the result of temperature induced changes in growth rate. These large scale variations do not explain the morphologically curved surfaces present in the stereom of echinoderm skeletal elements. Furthermore, the data of Jones $(1969,1972)$ indicate that the distribution of $\mathrm{Mg}$ in the magnesian calcite of sponge spicules is homogeneous at the level of resolution of EMPA, despite the curved nature of the spicules.

\section{MATERIALS AND METHODS}

Columnals of $N$. blakei were prepared in the following manner: 'crushed grain' mounts were prepared by grinding whole columnals in a mortar and pestle under liquid nitrogen. Crushed grain material was then distributed onto holey carbon support films on beryllium electron microscope grids. A thin film of carbon was evaporated onto the grids to eliminate charging by the electron beam. These crushed grain mounts were used for microanalysis and lattice fringe imaging. 'Ion-thinned' specimens for HVEM imaging were prepared from petrologic thin sections of skeletal calcite. A $3 \mathrm{~mm}$ support washer was attached to the material, and the surrounding thin section ground away. The washer with its attached disc of skeletal material was removed from the slide and further thinned in an argon ion mill. A thin film of carbon was then evaporated onto the specimen to prevent charging. 
Scanning Transmission Electron Microscopy (STEM) microanalytical studies were performed in order to determine the distribution of magnesium in the skeletal calcite. Crushed grain mounts were observed in a JEOL JEM-100CX AEM. Analyses for $\mathrm{Mg}$ and $\mathrm{Ca}$ were recorded in STEM mode and data were quantified using the Cliff-Lorimer (ratio) technique (Cliff and Lorimer, 1972). Quantitative analyses were performed at $100 \mathrm{kV}$ accelerating voltage and spectra were collected over $200 \mathrm{~s}$ counting times with a beam current of $0.5 \mathrm{nA}$. Areas chosen for analyses met the 'thin film criterion' (Goldstein, 1979) which holds for $\mathrm{Mg} / \mathrm{Ca}$ data in materials of this type which are of $300 \mathrm{nM}$ thickness or less. Results were analysed statistically by a technique developed for use with data of this type (Blake $e t$ al., 1983). Utilizing the STEM technique it is possible to achieve a lateral spatial resolution approaching $30 \mathrm{nM}$ in thin samples. However, carbonates are very susceptible to mass loss (electron beam damage) under these conditions and analyses reported here were recorded by scanning the beam over $100 \mathrm{nM}$ square areas of material.

\section{RESULTS}

Microareas of $N$. blakei skeletal calcite analysed using the STEM technique are remarkably uniform in composition. For example, for a sample size of $N=25$, the mean composition is $\mathrm{Ca}_{0.894} \mathrm{Mg}_{0.106} \mathrm{CO}_{3}$, with a standard deviation of 0.011 . This value agrees well with microprobe results for which an average composition of $\mathrm{Ca}_{0.88} \mathrm{Mg}_{0.12} \mathrm{CO}_{3}$ was determined. An $F$-test of the STEM data yields a value of $F=0.1232$ (degrees of freedom $(24,72)$ ), which supports the conclusion that the magnesium is uniformly distributed within individual skeletal elements at the sub- $\mu \mathrm{m}$ level. That is, the magnesium is not preferentially distributed with respect to the imperfections in structure known to exist from indirect measurements. Furthermore, these data demonstrate that organismal control of $\mathrm{Mg}$ incorporation cannot be responsible for the complex stereom microstructure ubiquitous in Echinodermata as has been previously hypothesized (O'Neill, 1981). While the echinoderm calcite is extremely homogeneous with respect to $\mathrm{Mg}$ incorporation, inorganic magnesian calcite cements analysed in analogous fashion are not. Table 1 shows statistical summaries of the echinoderm skeletal data and two examples of inorganic magnesian calcite data. (Data are from Blake et al., 1982a and Blake and Peacor, 1983.) As seen in Table 1, the inorganic magnesian calcites are highly heterogeneous in $\mathrm{Mg}$ incorporation when compared to the biogenic high magnesian calcite.

The mosaic structure of echinoderm calcite has been seen on natural surfaces (Towe, 1967) and demonstrated by rapid (Towe, 1967; Nissen, 1969) and stress-relaxed (O'Neill, 1981) fracturing, as well as by selected area electron diffraction (Blake and Peacor, 1981). However, the specific imperfections giving rise to the mosaic structure have never been observed in TEM micrographs of the skeletal material. This contrasts markedly with modern low-temperature inorganic magnesian calcites we have examined. The inorganic cements, which are mosaic composites of sub- $\mu \mathrm{m}$ sized crystallites, show a plethora of imperfection features not observed in the echinoderm skeletal material.

It is possible, however, that defects present in the echinoderm calcite are annealed out of the thin regions (those areas less than about $500 \mathrm{nM}$ thick) observable at $100 \mathrm{keV}$ accelerating voltage. We therefore utilized high voltage elec-

Table 1. Summary of STEM microanalytical data for high magnesian calcite (HMC) cements from inorganic and biogenic sources

\begin{tabular}{lcccc}
\hline Type of calcite & No. of Obs. & $\begin{array}{c}\text { Mean value } \\
\mathrm{MgCO}_{3}\end{array}$ & $\begin{array}{c}\text { S.D. } \\
\mathrm{MgCO}_{3}\end{array}$ & $\begin{array}{c}F \text {-test } \\
\text { results* }\end{array}$ \\
\hline Fresh water HMC† & 202 & $21.79 \%$ & $6.75 \%$ & $12.32(201,48)$ \\
Marine HMC & 97 & 14.1 & 3.41 & $1.29(96,96)$ \\
Echinoderm HMC & 25 & 10.6 & 1.1 & $0.12(24,72)$ \\
\hline
\end{tabular}

* Numbers in brackets refer to degrees of freedom for $F$-test.

+ Data are from Bear Creek No. 1 cement, Blake and Peacor (1983).

$\ddagger$ Data are from 'rip-up clast' cement, Blake et al. (1982a). 
tron microscopy (HVEM) to image the ionthinned columnals, in order to determine the presence or absence of dislocations in thicker regions of the calcite. Figure 2 is a representative micrograph of the material, recorded at $1.0 \mathrm{MeV}$ accelerating voltage. Dislocations and crystalline defects are conspicuously absent, even in bulk regions of the material. The 'mottling' of contrast seen in Fig. 2 (particularly along bend extinction contours) is also observed in micrographs taken at $100 \mathrm{keV}$. This heterogeneity of contrast may be due to unrequited stress in the crystalline material.

High resolution lattice fringe images of the crinoid calcite were taken to determine the nature of the mosaic boundaries which should be visible in lattice fringe images of the material. Figure 3 shows a lattice fringe image taken with axial illumination, with the crystal oriented so that several crystallographic planes are in contrast. The inset diffraction pattern shows the diffracting condition used to construct the image. On the left side of the micrograph, the crystal is oriented so that three different sets of planes $(01.2, \overline{1} 1 . \overline{2}$, and 10.4$)$ are in contrast, while on the right side only one set of planes (10.4) is in contrast. By viewing the figure with the page held parallel to the direction of view, and along the direction of the 10.4 planes, a slight but sharp change in orientation of the 10.4 planes is clearly visible along the boundary where the other two planes go out of contrast. We interpret this structure as two 'mosaic blocks' or crystallites of the mosaic structure which are slightly misoriented one to the other. The boundary between the two blocks is largely coherent and resembles a low angle grain boundary. Arrows point to dislocations which accommodate the slight misfit between the planes.

It is unlikely that a structure of this sort is an artifact of sample preparation or sample treatment and we interpret it to be a consequence of the mechanism of growth of the skeletal material. Such a structure, if pervasive, could give rise to all of the observations noted in previous reports of echinoderm fracture surfaces. The low angle

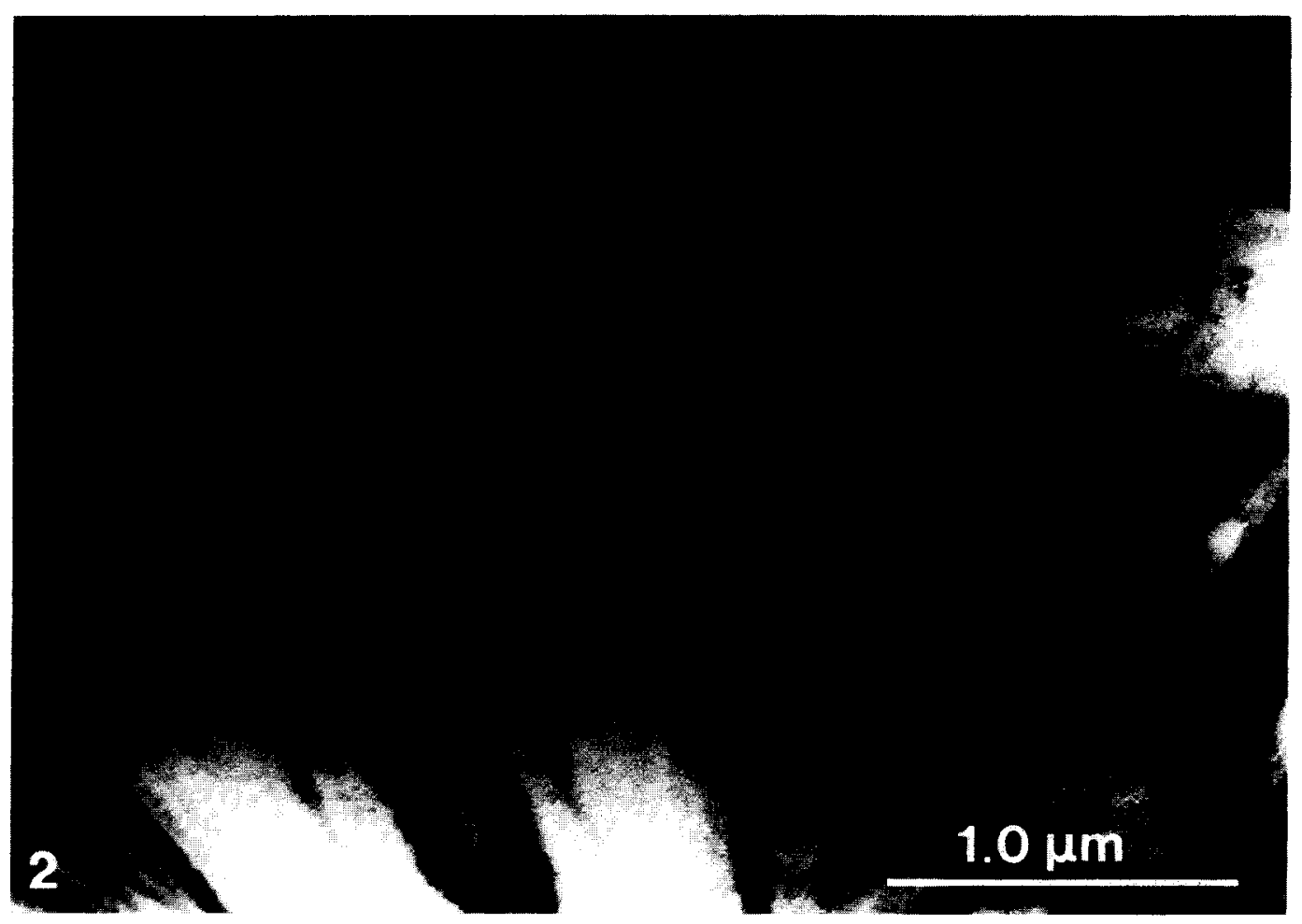

Fig. 2. High voltage $(1.0 \mathrm{MeV})$ bright field electron micrograph of $N$. blakei columnal. While indirect methods have shown that a pervasive mosaic structure exists, HVEM micrographs show a notable absence of dislocation networks which should exist as a consequence of the structure. The fine 'punctate' structure in the micrograph is due to electron beam damage and is not an original crystallographic feature of the calcite $(\times 38,000)$. 


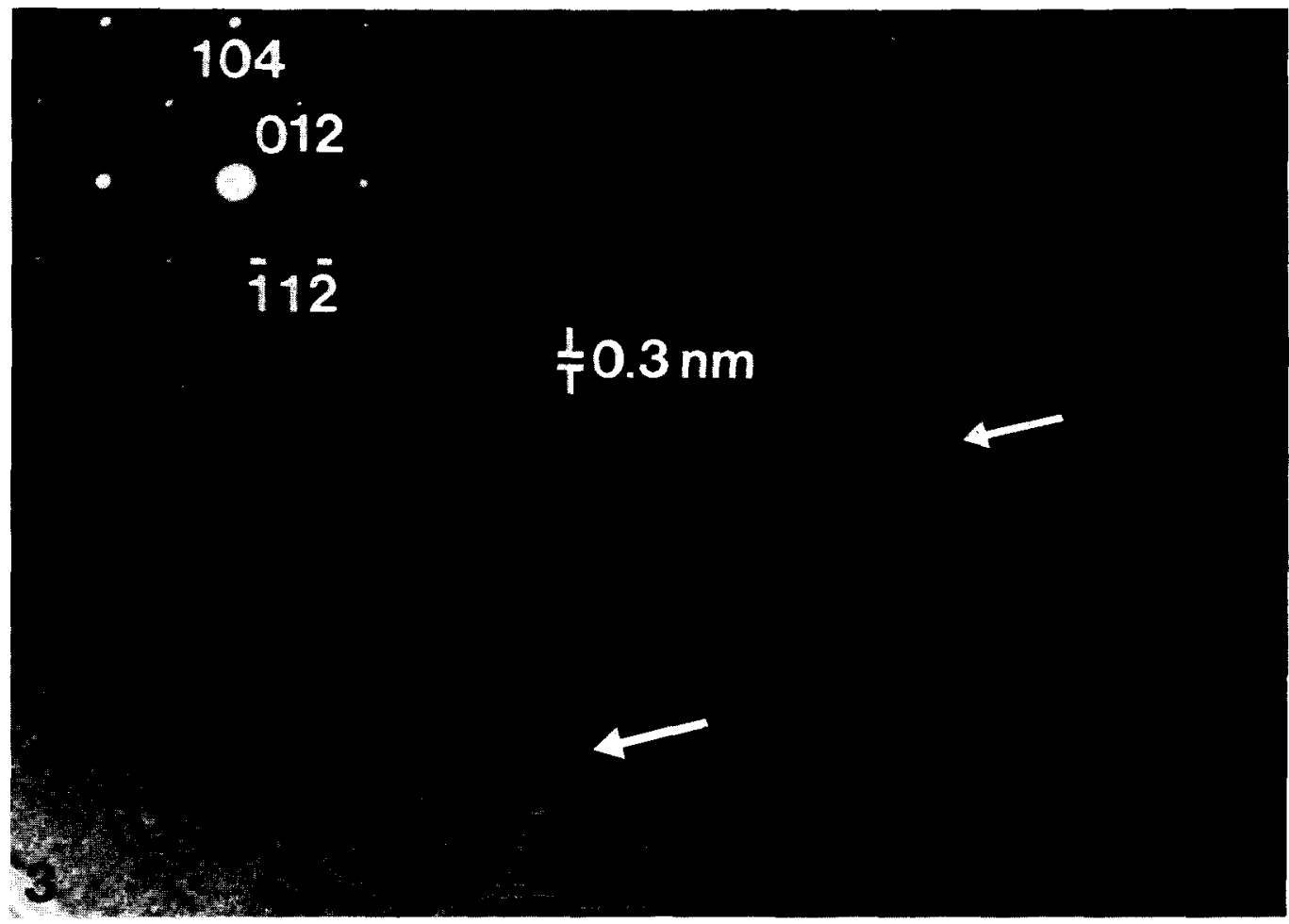

Fig. 3. High resolution TEM lattice fringe image of $N$. blakei columnal. Inset diffraction pattern shows the diffracting condition used to construct the image. The image is interpreted as two 'mosaic blocks' of the calcite, which are slightly misaligned one to the other. The boundary is coherent, with the exception of the areas marked by arrows. Arrows mark dislocations which act to reduce the stress caused by the abrupt change in orientation of the 10.4 planes as they cross the boundary between the two mosaic domains $(\times 4,180,000)$.

boundaries, constituting zones of weakness, could be the areas of crack nucleation and growth during stress relaxed fracturing. Under other conditions, fracture surfaces could exhibit conchoidal or 'mixed' fracturing depending on the magnitude and direction of the force applied. The slight misorientation of the crystallites would give rise to the mosaic spread of diffractions reported previously. Lastly, such a semicoherent structure, if regularly repeated over large volumes, could easily give rise to the continuous change in orientation of crystallographic axes, as noted previously in the ambulacral and interambulacral skeletal plates of some echinoids (Raup, 1966).

\section{DISCUSSION}

We conclude from the STEM microanalytical data that $\mathrm{Mg}$ distribution in columnals of $N$. blakei is strikingly homogeneous. The rounded morphology present in $N$. blakei stereom, and typical of all echnoderm skeletal elements, is therefore not the result of organismal control of variations in $\mathrm{Mg}$ incorporation.

We speculate that the pervasive mosaic structure is the result of small changes in the orientation of sub- $\mu \mathrm{m}$-sized crystallites, which despite their differences in orientation, are largely coherent. The presence of semi-coherent boundaries between mosaic domains, and the absence of major dislocation networks, indicate that the structure is in a state of stress. From our observations of the heterogeneous and imperfect ultrastructure and microchemistry of inorganic magnesian calcites, it is clear that biomineralization as it occurs in Echinodermata is not strictly a process of physico-chemical precipitation. There must be strong organismal control of both composition and structure at the sub- $\mu \mathrm{m}$ level during the biomineralization process.

The presence of such a 'stressed' lattice structure in echinoderm calcite implies that the skeletal material is in a higher energy state than 
would be a perfect crystal of the same composition. The mechanisms involved in the stabilization of biogenic and abiogenic magnesian calcite under diagenetic conditions are not well understood by carbonate petrologists. It is well known, however, that solution and chemical alteration of minerals and other inorganic compounds is initiated at sites which are either chemically or structurally inhomogeneous. If diagenesis occurs in chemically homogeneous materials, then the sites of crystal imperfection are attacked first. Blake et al. (1982b) present evidence from fossil echinoderm fragments suggesting that diagenesis of primary high magnesian calcite takes place via microdissolution-reprecipitation events, commonly with retention of $\mathrm{Mg}$ from the original skeletal material in microdolomite inclusions. It is highly unlikely that such microdolomites could result from a 'homogeneous dissolution' mechanism in such materials. Rather, we suggest that sites of structural stress or structural imperfection are attacked first, resulting in the nucleation of microdolomites throughout the stereom material.

In order to understand the mechanism of stabilization of skeletal material in the diagenetic environment, an ultrastructural as well as microchemical characterization of the initial mineral phase is required.

Acknowledgements-We thank Dr. Kenneth Towe of the Smithsonian Institution, Dr. Richard Reeder of SUNY, Stony Brook, Dr. Daniel Fisher of the Museum of Paleontology, University of Michigan and Dr. B. H. Wilkinson of the Department of Geological Sciences, University of Michigan for reviewing the manuscript. We thank Dr. Anthony Taylor and the staff of the DOE HVEMTandem National User Facility, Argonne National Laboratory, for assistance and machine time on the HVEM. Support under NSF EAR81-07529 (D.R.P.) and a Rackham predoctoral fellowship (D.F.B.) is gratefully acknowledged.

\section{REFERENCES}

Blake, D. F. and Peacor, D. R., 1981. Biomineralization in crinoid echinoderms: Characterization of crinoid skeletal elements using TEM and STEM microanalysis. SEM/1981/III, $321-328$.

Blake, D. F., Kocurko, M. J. and Peacor, D. R., 1982a Crystallography of Holocene magnesian calcite cements from the gulfcoast of Louisiana. Geol. Soc. Am. Abstr. W. Prog., 14 (7): 445

Blake, D. F., Peacor, D. R. and Wilkinson, B. H., 1982b. The sequence and mechanism of low-temperature dolomite formation: Calcian dolomites from a Pennsylvanian echinoderm. J. Sedim. Petrol., 52: 59-70.

Blake, D. F., Isaacs, A. I. and Kushler, R. H., 1983. A statistical method for the analysis of quantitative thin-film microanalytical data. J. Microsc., 131 (2): 249-256.

Blake, D. F. and Peacor, D. R., 1983. Microstructure and microchemistry of Holocene freshwater magnesian calcite and dolomite cements from the Coast Range of California. Geol. Soc. Am. Abstr. W. Prog., 16 (6): 527.

Cliff, G. and Lorimer, G. W., 1972. The quantitative analysis of thin metal foils using EMMA-4 - The ratio technique Proc. Fifth European Congress of EM, Inst. Physics, London, $140-141$

Davies, T. T., Crenshaw, M. A. and Heatfield, B. M., 1972. The effect of temperature on the chemistry and structure of echinoid spine regeneration. J. Paleont., 46 (6): 874-883.

Donnay, G. and Dawson, D. L., 1969. X-ray diffraction studies of echinoderm plates. Science, 166: 1147-1150.

Goldstein, J. I., 1979. Principles of thin-film microanalysis. In : Introduction to Analytical Electron Microscopy, Hren, J. J. et al. (eds.), Plenum Press, New York, 83-117.

Jones, W. C., 1969. An investigation of some calcareous sponge spicules by means of electron probe micro-analysis. Micron, 1: 34-39.

Jones, W. C., 1972. Examination of the large triacts of the calcareous sponge Leuconia nivea Grant by scanning electron microscopy. Micron, 3: 196-210.

Nissen, H., 1969. Crystal orientation and plate structure in echinoid skeletal units. Science, 166: 1150-1152.

O'Neill, P. L., 1981. Echinoderm calcite and its fracture mechanics. Science, 213, 646-648.

Raup, D. L., 1966. The endoskeleton. In: Physiology of Echinodermata, Boolootian, R. A. (ed.), Interscience, New York, 379-395.

Towe, K. M., 1967. Echinoderm calcite: Single crystal or polycrystalline aggregate. Science, 157: 1048-1050.

Weber, J. N., 1969. The incorporation of magnesium into the skeletal calcite of echinoderms. Am. J. Sci. 267: 537-566. 